\title{
POSREDOVANJE NATA V KRIZAH - IZKUŠNJE IN IZZIVI OPERACIJE V LIBIJI
}

\author{
NATO CRISIS INTERVENTIONS - \\ LESSONS LEARNED AND CHALLENGES \\ OF THE OPERATION IN LIBYA
}

Povzetek Po izbruhu nemirov v Libiji v začetku leta 2011 so v Varnostnem svetu ZN sprejeli resolucijo, ki je zagotovila mandat za mednarodno posredovanje v Libiji. Dva dni po sprejetju resolucije so ameriške, britanske in francoske sile začele operacije za vzpostavitev embarga in območja prepovedi letenja nad Libijo. Konec marca je poveljevanje in nadzor nad operacijo Združeni zaščitnik prevzel Nato, v njej so sodelovale vojaške sile 14 držav članic Nata in 4 partnerskih držav. Operacija je prispevala k zmanjšanju civilnih žrtev spopadov in pomagala opoziciji pri odstranitvi režima Moamerja Gadafija.

Operacija Združeni zaščitnik je primer učinkovitega posredovanja Nata v krizi, vendar je tudi opozorila na več težav in pomanjkljivosti glede strategije in glede vojaških zmogljivosti Nata pri izvajanju kriznega menedžmenta. V Natu so se pri obravnavi libijske krize pokazala različna stališča zaveznic, ki so privedla do resnih političnih razprav v zavezništvu. Vendar je bila kljub tem razlikam izvedba operacije mogoča. Operacija je opozorila na znatne pomanjkljivosti na področju vojaških zmogljivosti in na odvisnost evropskih zaveznic od vojaških zmogljivosti ZDA na nekaterih pomembnih področjih. Izkušnje operacije opozarjajo tudi na politična in vojaška vprašanja, s katerimi se bo Nato verjetno srečal ob podobnih operacijah v prihodnosti. Med zaveznicami je mogoče pričakovati različna stališča in pristope glede vloge Nata v prihodnjih krizah, kot tudi različno pripravljenost vojaško prispevati $\mathrm{k}$ operacijam. Za učinkovit krizni menedžment pa bo potrebno tudi več fleksibilnosti.

Ključne Nato, Libija, krizni menedžment, vojaške zmogljivosti, vojaške operacije.

besede

Abstract After the outbreak of civil unrest in Libya at the beginning of 2011, UN Security Council adopted resolution which authorized international intervention in Libya. Two days after the authorization, U.S., British and French forces launched operations to 
enforce embargo and no-fly zone over Libya. By the end of March NATO, took over command and control of the operation "Unified Protector", which was conducted by the armed forces of 14 NATO countries and 4 partner countries. The operation reduced the number of civilian casualties in conflict and supported the opposition to overthrow Muammar al-Qaddafi.

Operation "Allied Protector" is an example of NATO's effective intervention in crisis; however it also revealed shortcomings and impediments concerning NATO's crisis management strategy and military capabilities. NATO's approach to Libyan crisis demonstrated different positions among allies which resulted in serious political debates. Despite these differences NATO was able to launch the operation. The operation revealed serious deficiencies in military capabilities and European NATO members' dependency on the U.S. in some key military capabilities. Lessons from operation also point to political and military questions which NATO will probably face in the case of similar operations in the future. Concerning NATO's role in future crisis, different positions and approaches among allies could be expected as well as different levels of willingness to contribute military to operations. Effective crisis management will also require more flexibility.

Key words NATO, Libya, crisis management, military capabilities, military operations.

Uvod Nato je skozi celotno obdobje hladne vojne opravljal predvsem funkcijo obrambe zaveznic pred vojaškim napadom sil Varšavskega sporazuma. S spremembami po hladni vojni pa so se njegove funkcije bistveno spremenile. Zavezništvo se je začelo spopadati s širšim spektrom groženj, kot je zgolj vojaško ogrožanje ozemlja ene ali več članic. Obdobje po letu 1990 zaznamuje širitev funkcij Nata, hkrati pa tudi korenita sprememba njegovih struktur in pristopov $\mathrm{k}$ zagotavljanju varnosti. Zavezništvo se postopoma spreminja $v$ vse bolj univerzalno varnostno-politično organizacijo, ki se spoprijema z zagotavljanjem vojaških kot tudi nevojaških vidikov varnosti, njegove aktivnosti pa niso več vezane na območje držav članic, pač pa usmerjene v globalno delovanje za zagotavljanje mednarodne varnosti in stabilnosti.

O delovanju Nata, ki ne bo več usmerjeno izključno na kolektivno obrambo članic, so v zavezništvu začeli razmišljati že v prvi polovici devetdesetih let. Kot posledica možnega nastanka kriz in oboroženih konfliktov, ki bi zahtevali vojaško posredovanje, je bil oblikovan koncept operacij zunaj območja Nata (angl. out of area operations). Vojaške operacije Nata od sredine devetdesetih let obsegajo posredovanje v Bosni in Hercegovini po sklenitvi Daytonskega sporazuma leta 1995, posredovanje proti ZRJ leta 1999 in začetek operacije na Kosovu, operacijo v Makedoniji leta 2001, operacijo v Afganistanu od leta 2003 in operacijo v Libiji leta 2011. Vse operacije so bile $\mathrm{z}$ vojaškega in političnega vidika bistvene za umiritev razmer in vzpostavljanje pogojev za reševanje krize. 
Vojaško posredovanje je del aktivnosti kriznega menedžmenta, ki ga je Nato prvič uvrstil med svojih pet najpomembnejših nalog s Strateškim konceptom, sprejetim leta $1999,{ }^{1}$ čeprav je že pred tem posredoval v konfliktih na območju nekdanje Jugoslavije. V Natovem zadnjem strateškem konceptu, sprejetem v Lizboni leta 2010, je krizni menedžment poleg kolektivne obrambe in kooperativne varnosti ena izmed treh najpomembnejših nalog zavezništva. Obsega uporabo političnih in vojaških zmogljivosti v vseh fazah krize, ki bi lahko vplivala na varnost zavezništva (Strategic Concept, 2010, str. 8). Koncept odraža zavezanost članic Nata za posredovanje v krizah zunaj meja držav članic, kadar ocenijo, da je to potrebno. Tako posredovanje lahko obsega različne aktivnosti, vključno z uporabo vojaških sil.

Natova vojaška operacija v Libiji je opozorila na več težav pri njegovi sposobnosti vojaškega posredovanja. Gre za vprašanja ustreznosti vojaških zmogljivosti v Natu, hkrati pa tudi za politična vprašanja, ki se pojavljajo pri takih operacijah. V prispevku bomo na kratko prikazali kontekst in značilnosti operacije ter analizirali bistvena vprašanja vojaške in politične narave. Izkušnje operacije tudi nakazujejo težave, s katerimi se bo Nato verjetno srečal pri podobnih operacijah v prihodnje, zato bomo v zaključnem delu vprašanja zmogljivosti Nata za posredovanje v krizah obravnavali v širšem kontekstu razvoja nalog in zmogljivosti zavezništva.

\section{VOJAŠKO POSREDOVANJE V TEORETIČNI PERSPEKTIVI}

V sodobnosti se teoretično zanimanje za vojaško posredovanje (intervencijo) ${ }^{2}$ povečuje, še posebno zaradi sprememb v mednarodni politiki po koncu hladne vojne. Da intervencija vključuje poseg v suverenost in notranje zadeve neke države, v mednarodnih odnosih ni novo. Z zgodovinsko-teoretičnega vidika so pogosto obravnavane številne intervencije $\mathrm{v}$ zadnjih 200 letih. V tem prispevku se bomo omejili le na ugotovitev, da so razmere po koncu hladne vojne dale zagon praksi vojaške intervencije v notranjih konfliktih in da humanitarni vzroki postajajo vse bolj pomembna spodbuda za take intervencije. Suverenost države postaja vse manj uporaben koncept pri preprečevanju zunanje intervencije, sploh če gre za intervencijo zaradi humanitarnih vzrokov (Finnemore, 1996, in Arnold, 2008).

Pri preučevanju prakse vojaških intervencij v zadnjih dveh stoletjih Finnemore (1996) ugotavlja, da se praksa intervencij spreminja. V preteklosti so bili motivi za intervencije predvsem geostrateški oziroma ekonomski interesi intervenirajočih

\footnotetext{
Strateški koncept iz leta 1999 je opredelil pet glavnih nalog zavezništva: varnost (zagotavljanje stabilnega evro-atlantskega varnostnega okolja in demokratičnih institucij ter mirno reševanje sporov); posvetovanje (med zaveznicami glede varnostnih ali drugih vprašanj); odvračanje in obramba (pred agresijo na katerokoli članico, kot je opredeljeno v 5. členu Severnoatlantske pogodbe); krizni menedžment (pripravljenost prispevati $k$ preprečevanju konfliktov, vključno z aktivnim angažiranjem $v$ operacijah kriznega odzivanja) in partnerstvo (z državami nečlanicami na evro-atlantskem območju) (Strategic Concept, 1999).

2 V slovenskem jeziku je uveljavljen izraz posredovanje, v tuji znanstveni literaturi pa se uporablja izraz intervencija (angl. intervention). V članku enakovredno uporabljamo oba izraza. O intervenciji govorimo predvsem $v$ teoretičnem delu, v nadaljevanju pa za iste aktivnosti uporabljamo izraz posredovanje.
} 
držav, ${ }^{3}$ zdaj pa postajajo pomembni tudi humanitarni vzroki. Nastal je izraz humanitarna intervencija, ki jo razumemo kot uporabo vojaške sile za zaščito življenj in blaginje civilistov v drugi državi (Finnemore, 1996, opomba 2 na str. 154). Države se vključujejo v izvajanje intervencij tudi v krizah, v katerih nimajo neposrednih ekonomskih in geostrateških interesov, kar je posledica spremenjenega normativnega konteksta; v zadnjih stopetdesetih letih smo priča procesom, ki vodijo do razvoja logično in moralno utemeljenih sklopov norm, povezanih s človekovimi pravicami in humanitarno intervencijo, ki se postopoma institucionalizirajo v mednarodnih institucijah in organizacijah (Finnemore, 1996, str. 156). Če torej humanitarna zaščita pomeni neke vrste normativno opredeljeno dolžnost mednarodne skupnosti, to še ne pomeni, da bo do intervencije vedno prišlo. Humanitarni motivi niso nujno poglavitni za ravnanje držav. Najpogosteje so motivi za intervencijo različni. Humanitarni motivi so del širšega spleta motivov, ki usmerjajo ravnanje držav (Finnemore, 1996, str. 156); pogosto ne pride do humanitarnega delovanja, če bi bilo to $\mathrm{v}$ nasprotju $\mathrm{z}$ drugimi cilji ali interesi države (prav tam, str. 162).

Pomembna značilnost humanitarne intervencije je razvoj prakse multilateralizma. Tudi v preteklosti so bile nekatere intervencije multilateralne, vendar predvsem zato, ker so intervenirajoče sile želele preprečiti prevladujoč vpliv posamezne sile na nekem območju. $\mathrm{V}$ sodobnosti multilateralizem postane ena najpomembnejših norm: humanitarna vojaška intervencija mora biti multilateralna, da bi bila legitimna. Finnemore (1996, str. 165) ugotavlja, da v prid multilateralizmu ne govorijo vojaški, pač pa predvsem politični razlogi: z vidika učinkovitosti ni jasnih prednosti multilateralizma; izbira temelji predvsem na dojemanju politične sprejemljivosti in politične cene. Multilateralizem je postal v 20. stoletju institucionaliziran, tako da je unilateralna intervencija postala nesprejemljivo draga (v političnem smislu). Glede na uveljavljene norme je v sodobnem svetu uporaba vojaške sile upravičena samo, če gre za skupno multilateralno delovanje in če je to posledica odločitve, sprejete v ustreznih mednarodnih forumih.

Teoretične obravnave intervencije opozarjajo tudi na spremembe pravno-normativnih okvirov in vrednot, ki spreminjajo pojmovanje suverenosti države. Arnold (2008, str. 190) opozarja na zapleten kontekst spreminjanja suverenosti:

»Hkrati z informacijsko tehnologijo in finančno revolucijo so pridobile na moči nove ideje glede človekovih pravic in varnosti, ki so v koliziji s starim razumevanjem nedotakljivosti suverenosti države. K temu je treba dodati še nastajajoč korpus mednarodnega prava in jasno je, da so šteti dnevi državnim voditeljem, ki izvajajo grozodejstva in se skrivajo za državno suverenostjo. Suverenost države je postala pogojna, kar pomeni, da se od državnih voditeljev pričakuje, da sprejemajo univerzalno sprejete standarde dobrega vladanja. S tem pa naraščajo pričakovanja, da bo

\footnotetext{
Tako so na primer velike evropske sile v 19. stoletju izvedle nekaj skupnih intervencij v Otomanskem cesarstvu, da bi si zagotovile nadzor nad dogajanji na tem območju, preprečevale druga drugi, da bi tu vzpostavile prevladujoč vpliv in da bi nadzirale druga drugo.
} 
sedaj mednarodna skupnost intervenirala, kadar gre za kršitev teh pogojev suverenosti, če je potrebno, tudi z vojaško silo.«

Navedene spremembe skupaj z odpravo blokovske delitve v hladni vojni, ki je omejevala možnost intervencij, vzpostavljajo pogoje, v katerih je več verjetnosti, da bo mednarodna skupnost posredovala v primeru humanitarnih kriz. Vendar isti avtor dodaja, da kljub temu obstaja znatna zadržanost držav do intervencije zaradi več dejavnikov. Vojaške intervencije so postale v vojaškem in političnim smislu bolj tvegane, ker so, kot kažejo izkušnje v zadnjih dveh desetletjih, intervencije lahko neuspešne (na primer Irak) in ne pripeljejo do želenih rešitev, temveč stanje še poslabšajo. Tveganje se povečuje tudi zaradi dostopnosti vojaške tehnologije in oborožitve, predvsem orožja za množično uničevanje, različnim nedržavnim akterjem, ki so lahko nasprotniki izvajalcem intervencije (Arnold 2008, str. 190).

V sodobnosti smo priča dejstvu, da je pravzaprav bolj verjetno kot v preteklosti, da bo prišlo do mednarodne vojaške intervencije v nekem konfliktu, na kar kaže tudi nekaj primerov operacij Nata. Po drugi strani pa se na številne še tako obsežne in krvave konflikte mednarodna skupnost ni odzvala z vojaško intervencijo. Teoretične obravnave so samo analitični okvir, s katerim je mogoče presojati posamezen konflikt ter sklop dejavnikov, ki opredeljuje odziv mednarodne skupnosti na konflikt.

V teoretičnih analizah zasledimo tudi prepričanje, da so v sodobnosti za uporabo intervencije in njen nadaljnji razvoj pomemben dejavnik izkušnje pri uspešnosti preteklih intervencij. Arnold (2008, str. 203-6) navaja sedem meril uspešnosti intervencije. Prvič, intervencija mora biti pravična in mora imeti politično legitimnost, ki jo zagotovi Varnostni svet ZN ali ustrezna regionalna organizacija. Drugič, izčrpani morajo biti vsi drugi načini reševanja konflikta. Tretjič, intervencija mora biti izvedljiva in mora izboljšati okoliščine, ki so do nje privedle. Četrtič, na strani tistih, ki izvajajo intervencijo, mora obstajati politična odločenost, ki je ne smejo omajati zmanjšanje podpore domače javnosti, žrtve ali bolj dolgotrajno delovanje od predvidenega. Petič, obstajati mora jasen političen cilj intervencije, ki ga je mogoče prevesti v nedvoumno vojaško nalogo za poveljujočega ter trdna pravila delovanja z jasno oblikovanimi omejitvami glede uporabe vojaške sile. Šestič, intervenirajoče sile morajo imeti zagotovljeno enotnost poveljevanja. Sedmič, treba je zagotoviti zadostne vojaške zmogljivosti za uspešno izvedbo intervencije.

Predstavljeni teoretični okvir je lahko tudi podlaga za razumevanje Natovih posredovanj v preteklih konfliktih in za analizo možnih dilem v prihodnje. Nato je multilateralna vojaško-politična organizacija s stalno vojaškopoveljstveno strukturo in silami, ki se pripravljajo in urijo za skupno delovanje. Kot tak je v svetu edinstvena organizacija glede sposobnosti kolektivnega vojaškega delovanja v primeru konfliktov. V večini Natovih posredovanj, predvsem pa v zračni operaciji proti Zvezni republiki Jugoslaviji leta 1999 in operaciji v Libiji 2011, so bili pomemben motiv humanitarni vzroki: zaščita civilnega prebivalstva v oboroženem konfliktu. Z vojaškega vidika so bili posegi Nata $\mathrm{v}$ preteklosti razmeroma uspešni, vendar pa smo priča tudi 
dolgotrajni nestabilnosti, potem ko se vojaški poseg končal. Ob zavedanju pomanjkljivosti samo vojaškega delovanja v krizah so v Natu v tem desetletju začeli razvijati tako imenovani celostni pristop (angl. Comprehensive Approach) h kriznemu menedžmentu. Tak pristop obsega kombinacijo civilnih, političnih in vojaških instrumentov v reševanju kriz in sodelovanje s civilnimi partnerji ter mednarodnimi organizacijami (predvsem EU in Združenimi narodi), partnerskimi državami in drugimi. Pristop je usmerjen predvsem v povečanje sposobnosti stabilizacije razmer in vzpostavitev državnih struktur tam, kjer Nato skupaj z mednarodno skupnostjo prispeva k normalizaciji razmer po konfliktih (Nato - Comprehensive Approach, 2013). Izkušnje Natovih operacij po eni strani kažejo na razvoj potencialov za mednarodno vojaško posredovanje v konfliktih, po drugi strani pa opozarjajo na številne težave in odprta vprašanja glede takega posredovanja.

\section{NEMIRI V LIBIJI IN NATO}

Upor proti režimu v Libiji vsebinsko spada v kontekst tako imenovane arabske pomladi, serije nemirov ter političnih in družbenih sprememb v več državah Severne Afrike in Bližnjega vzhoda. Šlo je za širitev upora državljanov proti večinoma avtokratskim vladavinam, slabim ekonomskim razmeram, kratenju človekovih pravic, korupciji itn. Uporniško gibanje je v zelo kratkem času zajelo večje število držav, v vsaki pa gre za specifičen preplet vzrokov upora. Najprej je decembra 2010 prišlo do upora v Tuniziji. Upor ljudskih množic je bil neposreden odgovor na rast nezaposlenosti, slabšanje ekonomske situacije in razraslo korupcijo. Januarja 2011 so se v Egiptu začela množična zborovanja z zahtevo po odpravi režima Hosnija Mubaraka, približno v istem času pa se je začel tudi upor proti režimu v Libiji. Marca 2011 so se začele demonstracije proti režimu v Siriji. Množični protesti so zajeli tudi Jemen, Bahrajn, Alžirijo, Jordanijo, Oman in Maroko. Kot skupni imenovalec vzrokov arabske pomladi pogosto navajajo nedemokratične oblike vladavin in kratenje človekovih pravic. Na takšne oblike vladavine je dolgo časa pristajal tudi Zahod, zato je bil tudi odziv Zahoda na dogajanja po začetku arabske pomladi precej ambivalenten. Roth (2012: str. 3-7) opozarja, da so bile zahodne vlade do avtokratskih režimov v tej regiji pravzaprav strpne. Dopuščale so tako imenovano »arabsko izjemo« glede uveljavljanja demokracije, ker so bile prepričane, da avtokratski režimi z zagotavljanjem stabilnosti bolje služijo zahodnim interesom v regiji. Takšna politika Zahoda je temeljila na prepričanjih, da ti režimi varujejo Zahod pred grožnjami političnega Islama; pomagajo v boju proti terorizmu; zagotavljajo način sožitja z Izraelom; zagotavljajo najboljši način za preskrbo z nafto ter pomagajo Zahodu pri zaustavljanju migracij iz regije. Navedena prepričanja $\mathrm{v}$ politiki Zahoda nam pomagajo razumeti zadržanost in ambivalenten odnos evropskih držav in ZDA do dogajanja v okviru arabske pomladi.

V začetku leta 2011 se je začel upor proti režimu v Libiji. Zaradi stanja v državi, avtoritarne vladavine režima Moamerja Gadafija, vse bolj razširjene korupcije in drugih težav so se nemiri, deloma spodbujeni tudi s predhodnimi vstajami $\mathrm{v}$ Tuniziji in Egiptu, sredi februarja začeli v Bengaziju na severovzhodu države in se postopoma širili po državi. Nasilni odziv režima na zahteve protestnikov je povzročil 
stopnjevanje nemirov in konec februarja privedel do obsežnih oboroženih konfliktov. Uporniške skupine so takrat zavzele nekaj mest, med drugim Misrato in Zawiyah, čemur je sledil protinapad vladnih sil. Naraščalo je število žrtev, ki je v začetku marca doseglo že več sto mrtvih $^{4}$, povečevala se je humanitarna kriza, naglo je naraščalo tudi število beguncev, ki je do začetka marca že preseglo 350.000 (WHO Mothly, 2011). Naslednje mesece so zaznamovali obsežni oboroženi spopadi, v katerih so 23. avgusta 2011 uporniki zavzeli libijsko prestolnico Tripoli. 16. septembra 2011 so Združeni narodi priznali Nacionalni prehodni svet (National Transitonal Council) kot legitimno oblast v Libiji, ki je nadomestila režim Moamerja Gadafija. Ta je bil na begu in so ga 20. oktobra 2011 ubili. Nacionalni prehodni svet je 23. oktobra 2011 uradno razglasil konec državljanske vojne v Libiji, vendar tudi po tem država ostaja politično in varnostno zelo nestabilna.

Položaj v Libiji je že od vsega začetka sprožal vprašanje odziva mednarodne skupnosti, vendar je obstajala precejšnja neenotnost glede tega, kako se odzvati, predvsem pa zadržanost glede vojaškega posredovanja. Ob izbruhu nemirov v Libiji se je tudi EU odzvala neodločno, glede odziva na krizo pa so med pomembnimi članicami obstajala precej nasprotujoča si stališča. Medtem ko sta se Velika Britanija in Francija zavzemali za posredovanje in poskušali za to pridobiti tudi ZDA, je bilo stališče visoke predstavnice EU za zunanjo in varnostno politiko Catherine Ashton sprva odklonilno zaradi nasprotovanja članic EU Nemčije in Italije ter tudi zaradi nasprotovanja nekaterih drugih držav, predvsem članic Nata, med njimi tudi Turčije (Santini in Varvelli, 2011).

V Natu so se odzvali na krizo, najprej z uradnim stališčem, ki je izražalo zaskrbljenost, vendar niso izrazili namena za posredovanje. 25. februarja se je Severnoatlantski svet sestal na nujnem posvetovanju, generalni sekretar Nata pa je omenjal možno posredovanje za izvedbo evakuacije in morda tudi humanitarne pomoči. ${ }^{5} \mathrm{~V}$ začetku marca je Nato okrepil zračni nadzor v Sredozemlju.

Za odziv mednarodne skupnosti so bile odločilne razprave v Združenih narodih, na katerih so 26. februarja 2011 sprejeli Resolucijo 1970, ki je uvedla zamrznitev premoženja in omejitev potovanja za Gadafija ter za najožji politični vrh in vzpostavitev embarga za promet z orožjem. Nato so 17. marca sprejeli Resolucijo 1973, ki je zagotovila mandat za mednarodno posredovanje v konfliktu. Vzpostavila je območje prepovedi letenja nad Libijo, da bi tako preprečili delovanje vladnih zračnih sil proti upornikom. Okrepila je tudi ukrepe za izvajanje embarga za promet z orožjem in za nadzor pomorskega prometa. Izrecno pa je izključevala okupacijo Libije, torej kopenski poseg na ozemlju države. Namen resolucije je bil odobriti uporabo sile za

\footnotetext{
4 Prva dva tedna spopadov sta po različnih ocenah zahtevala od nekaj sto do dva tisoč smrtnih žrtev. Tudi sicer se podatki o skupnih žrtvah vojne v Libiji leta 2011 zelo razlikujejo. Publikacija Conflict Barometer (2011) navaja, da se ocene gibljejo od 10.000 do 50.000 žrtev. Različni spletni viri navajajo precej različne podatke: tako zasledimo oceno 30.000 smrtnih žrtev v obdobju od 15. februarja do 8. septembra 2011; pa tudi oceno 25.000 v obdobju od 15. februarja do 2. oktobra 2011. http://en.wikipedia.org/wiki/Casualties_of_the_Libyan_ civil_war\#cite_note-flee-2.

5 Kronologija dogodkov je dostopna na Natovi spletni strani: http://www.nato.int/cps/natolive/71679.htm.
} 
zaščito civilnega prebivalstva v Libiji, torej poudarjeno humanitaren. Sprejeto resolucijo obravnavajo kot prvi primer odobritve uporabe sile za take namene (Bellamy in Williams, 2011).

Vojaško posredovanje se je začelo že dva dni po sprejetju Resolucije 1973 z napadi francoskih, ameriških in britanskih letalskih ter pomorskih sil na objekte zračne obrambe v Libiji in na vojaške sile libijskega režima v okolici Bengazija. Do 31. marca, ko je vodenje operacije prevzel Nato, so te aktivnosti potekale kot večnacionalna operacija, pri kateri je prihajalo do znatnih nejasnosti glede vodenja in poveljevanja. $\mathrm{V}$ tej fazi je vodenje operacij prevzelo ameriško poveljstvo za Afriko (USAFRICOM), ki pa se je zaradi pomanjkanja izkušenj z vodenjem takih operacij in premajhnih zmogljivosti moralo spopasti s številnimi težavami (Baltrusaitis in Duckenfield, 2012, str. 29). V Natu so medtem še potekale razprave o njegovi morebitni vlogi pri posredovanju v Libiji. ${ }^{6}$ 24. marca je bilo v zavezništvu doseženo soglasje o prevzemu poveljstva nad operacijo v Libiji, 31. marca pa je zavezništvo začelo poveljevati operaciji, ki so jo poimenovali Združeni zaščitnik (Unified Protector). Tudi po tem, ko je poveljevanje operacije prevzel Nato, so se v začetni fazi pojavljala vprašanja glede sporazumov o poveljevanju mednarodnim silam, predvsem pa so izvajanje operacije spremljale težave zagotavljanja ustreznih vojaških zmogljivosti.

V operaciji, ki je trajala do 31. oktobra 2011, je sodelovalo 14 držav članic Nata, od tega dve državi samo v operacijah pomorskega embarga (pregled sodelujočih držav je v tabeli 1). V izvajanje operacije se je vključila samo polovica držav članic Nata. Ključna za sodelovanje je bila politična pripravljenost oziroma podpora države operaciji in njene vojaške zmogljivosti. V primeru te operacije sta dve pomembni članici Nata, Nemčija in Poljska, od vsega začetka nasprotovali operaciji, po drugi strani pa sta bili Velika Britanija in Francija vodilni zagovornici posredovanja $\mathrm{v}$ Libiji. Tudi pri izvajanju operacije sta ti dve državi imeli glavno vlogo. Njune zračne sile so opravile več kot 40 odstotkov vseh poletov in uničile več kot tretjino vseh tarč (Daalder in Stavridis, 2012).

Operacija je glede na svoj značaj zahtevala specifične zračne in pomorske vojaške zmogljivosti, sposobne delovanja nad ozemljem Libije in v Sredozemskem morju. V operacijo so bile vključene predvsem vojaške sile večjih in srednjih držav članic Nata. Pri izvedbi je šlo tudi za različno delovanje sil. Tako so tri članice Nata (Nizozemska, Španija in Turčija) s svojimi letali zagotavljale le vzpostavitev prepovedi letenja, niso pa sodelovale $v$ napadih na cilje na ozemlju Libije. V operacijo so napotile svoje zračne sile tudi štiri nečlanice Nata.

Čeprav Resolucija 1973 ni dopuščala kopenskega delovanja, je bilo v okviru operacije na ozemlju Libije tudi manjše število pripadnikov vojsk sodelujočih držav. Iz dostopnih virov je razvidno, da je šlo za manjše število vojaških svetovalcev in pripadnikov posebnih sil (ISS Comment, 2011). Poročilo organizacije Human Rights

${ }^{6}$ Francija je v tem obdobju predlagala, da bi operacijo izvajala Evropska unija pod poveljevanjem Francije in Velike Britanije. 
Watch navaja, da so Francija, Katar in Združeni arabski emirati ter verjetno še druge države zagotavljali orožje in urjenje opozicijskim silam; Katar pa je pozneje tudi priznal, da je napotil na ozemlje Libije več sto pripadnikov svoje vojske (Human Rights Watch, 2012, str. 596).

\begin{tabular}{|c|c|c|c|}
\hline \multirow{22}{*}{$\begin{array}{r}\text { Preglednica 1: } \\
\text { Sodelujoče } \\
\text { države } \vee \\
\text { operaciji } \\
\text { Združeni } \\
\text { zaščitnik }\end{array}$} & Države & Zračne operacije & Pomorski embargo \\
\hline & \multicolumn{3}{|l|}{ članice Nata } \\
\hline & Belgija & + & + \\
\hline & Bolgarija & & + \\
\hline & Danska & + & \\
\hline & Francija & + & + \\
\hline & Grčija & + & + \\
\hline & Italija & + & + \\
\hline & Kanada & + & + \\
\hline & Nizozemska & $(+)$ & + \\
\hline & Norveška & + & \\
\hline & Romunija & & + \\
\hline & Španija & $(+)$ & + \\
\hline & Turčija & $(+)$ & + \\
\hline & Velika Britanija & + & + \\
\hline & ZDA & + & + \\
\hline & \multicolumn{3}{|l|}{ nečlanice Nata } \\
\hline & Jordanija & $(+)$ & \\
\hline & Katar & $(+)$ & \\
\hline & Švedska & $(+)$ & \\
\hline & Združeni arabski emirati & + & \\
\hline & \multicolumn{3}{|c|}{+ - sodelovala $(+)$ - sodelovala samo v zagotavljanju prepovedi letenja } \\
\hline
\end{tabular}

Vir: Daadler, Stavridis, 2012 in spletna stran http://www.nato.int/cps/en/natolive/71679.htm

Operacija je imela tri temeljne cilje: zagotavljati zaščito civilnega prebivalstva in vzdrževati prepoved letenja, kar je bilo doseženo z zračnimi silami, ter izvajati embargo nad prometom $\mathrm{z}$ orožjem in prihodom plačancev, kar so zagotavljale pomorske sile $\mathrm{z}$ nadzorom nad dostopi do libijskih ozemeljskih voda. V operaciji je skupaj sodelovalo okoli 260 zračnih plovil in 21 ladij. Opravljenih je bilo 26.500 poletov, od tega 9700 za napade na objekte na ozemlju Libije. V zračnih napadih je bilo uničenih 5900 vojaških tarč, od tega 400 raketnih ali artilerijskih orožij, 600 tankov ali oklepnih vozil in okoli 400 vojaških poveljniških ali nadzornih centrov na ozemlju Libije. V pomorski blokadi pa so spremljali več kot 3000 ladij, okoli 300 pa 
so jih tudi pregledali. 11 ladjam so zavrnili odhod ali dostop v libijske ozemeljske vode (Nato and Libya, 2011).

V začetni fazi so bile zračne operacije usmerjene na uničenje protiletalske obrambe libijske vojske, ki bi lahko ogrožala letala zaveznic. Vzdrževanje zapore zračnega prostora nad Libijo je preprečevalo napade libijskih zračnih sil na civilno prebivalstvo in upornike. Napadi na libijsko ozemlje so bili usmerjeni na vojaške cilje, ki bi lahko pomenili grožnjo civilnemu prebivalstvu in upornikom. Delovanje zaveznic proti libijski vojski je bilo tudi pomemben vojaški dejavnik pri doseganju končnega cilja upornikov, to je odstranitve režima Moamerja Gadafija. Nato je operacijo končal 31. oktobra 2011.

\section{OPERACIJA ZDRUŽENI ZAŠČITNIK - PREVERJANJE STRATEGIJE IN ZMOGLJIVOSTI}

Dogajanja ob krizi v Libiji so primer hitrega in precej učinkovitega mednarodnega odziva ter tudi primer uspešnega vojaškega posredovanja Nata v krizi. Posredovanje Nata pa je opozorilo tudi na več vprašanj glede njegove pripravljenosti in sposobnosti za take naloge. Številne analize operacijo Združeni zaščitnik obravnavajo kot primer, ki kaže tudi na resne omejitve zavezništva pri izvajanju vojaških operacij kriznega menedžmenta v prihodnje. Pri pripravah in izvajanju operacije se je namreč pokazalo več težav politične in vojaške narave.

Z izbruhom spopadov v Libiji se je mednarodna skupnost srečala z vprašanjem, kako se odzvati na naraščajočo krizo. Nejasnosti in nasprotujoča si stališča so se izražala že v obravnavi libijske krize v Varnostnem svetu ZN, nasprotna stališča pa so zavzele tudi pomembnejše članice Nata. Velika Britanija in predvsem Francija sta se aktivno zavzemali za vzpostavitev zapore zračnega prostora, Nemčija pa je odločno nasprotovala kakršnemu koli vojaškemu posredovanju. Nemško stališče je bilo odraz tradicionalnega odpora do vojaškega posredovanja v svetu in prepričanja, da nemška javnost takega posredovanja ne bi podprla (Baltrusaitis in Duckenfield, 2012, str. 33). Različna stališča članic Nata so se odrazila tudi ob glasovanju za resolucijo 1973. Nemčija je bila ena izmed petih nestalnih članic Varnostnega sveta, ki so se glasovanja vzdržale. ${ }^{7}$ Tudi ZDA so bile do posredovanja sprva zadržane, vendar so svoje stališče pozneje spremenile. ${ }^{8}$

Sprejetju resolucije so sledile precej intenzivne razprave v Natu, ki jih ocenjujejo kot največjo krizo v zavezništvu po letu $2003 .{ }^{9}$ Predvsem so se razlikovala stališča

\footnotetext{
Za resolucijo je glasovalo deset članic Varnostnega sveta, vzdržalo pa se jih je pet: poleg Nemčije še Brazilija, Kitajska, Indija in Rusija.

8 ZDA so možnost vojaškega posredovanja v Libiji podprle po 12. marcu, ko je Arabska liga pozvala Varnostni svet ZN $k$ vojaškemu posredovanju v Libiji.

9 Takrat je prišlo do izrazitih nesoglasij med zaveznicami glede Natove vojaške zaščite Turčije ob ameriškem napadu na Irak. Tej zaščiti so nasprotovale Nemčija, Belgija in Francija, ker so ocenile, da bi to bilo mogoče razumeti, kot da odobravajo napad na Irak.
} 
članic glede narave vojaškega posredovanja. Čeprav je resolucija 1973 zagotavljala mandat za uporabo vojaške sile, je večina zaveznic bolj podpirala izvajanje pomorskega embarga in vzpostavitev prepovedi letenja kot pa napade na cilje na kopnem. Zaveznice so bile zaskrbljene tudi glede morebitnega odziva arabskih držav na vojaško posredovanje v Libiji (Baltrusaitis in Duckenfield, 2012, str. 30).

Resolucija 1973 je mednarodnim silam zagotovila mandat za uporabo vojaške sile za zaščito civilistov. Izvajanje vojaških operacij proti vladnim silam seveda privede do vprašanja, koliko operacije poleg mandata zaščite civilistov prispevajo tudi k izidu spopada. Cilji zaveznic so bili različni. Predvsem so se razlikovali glede tega, ali je cilj operacije tudi odstranitev Gadafija, česar mandat operacije ni obsegal. Toda zaveznice, ki so imele glavno vlogo v operaciji, so imele jasen namen strmoglaviti Gadafija, česar pa niso mogle jasno izraziti (ISS Comment, 2011). Nedvomno je operacija zavezništva znatno pripomogla k uspehu upornikov in odstranitvi Gadafijevega režima. Tako je bil presežen le humanitarni cilj operacije. Pokazalo se je, da je težko osredotočiti delovanje le na doseganje humanitarnih ciljev, torej na zaščito civilnega prebivalstva, ne da bi širše posegali v vojaško-politični izid spopada.

Z vojaškega vidika se je glavno vprašanje glede izvajanja operacije nanašalo na sposobnost zagotovitve ustreznih vojaških zmogljivosti ob omejeni podpori ZDA. Potem ko je bila libijska zračna obramba onesposobljena, ZDA v zračnih napadih na cilje na kopnem niso več sodelovale. V nadaljevanju so ZDA s svojimi vojaškimi zmogljivostmi opravljale zgolj podporno vlogo. Zagotovile so zmogljivosti na področjih obveščevalne dejavnosti, nadzora in izvidovanja (angl. intelligence, surveillance and reconnaissance - ISR) ter zmogljivosti oskrbe letal z gorivom v zraku. Toda te zmogljivosti so bile bistvene za izvedbo operacije, s čimer se je jasno pokazala odvisnost Nata od ameriške podpore.

Do težav pri izvajanju operacije je prišlo tudi zaradi odločitve Nemčije, da v operaciji ne bo sodelovala in je tudi odrekla razpoložljivost nemških posadk v letalih AWACS. Letala so skupna zmogljivost Nata, upravljajo pa jih mednarodne posadke, zato je umik nemških članov posadk znatno zmanjšal zmožnost delovanja teh letal. Težavo je bilo treba rešiti z nadomeščanjem nemškega osebja z osebjem iz drugih držav. V zameno je Nemčija okrepila svoje posadke v Natovi operaciji v Afganistanu, kar je omogočilo Natu, da ljudi, ki so sodelovali tam, uporabi v operaciji v Libiji.

Operacija je pokazala tudi šibkost evropskih zaveznic glede sposobnosti izvajanja trajnejših operacij, saj je začelo primanjkovati natančno vodenega streliva. Potem ko je bilo v Libiji uporabljenih več kot 2000 kosov natančno vodenega streliva, so se nekatere članice znašle pred težavo pomanjkanja tega streliva. Tako sta Danska in Norveška prek Natove agencije za oskrbo zaprosili za dodatne količine, ki sta jih zagotovili ZDA in Nemčija (Harding in Day, 2011, Baltrusaitis in Duckenfield 2012, str. 38). Po navedbah virov so večino od 7700 bomb in raket $\mathrm{z}$ natančnim vodenjem, ki so bile uporabljene v Libiji, zagotovile ZDA (Schmitt, 2012). V zmogljivostih 
evropskih članic Nata so se pokazale tudi znatne pomanjkljivosti na področju zagotavljanja obveščevalnih analiz, določanja ciljev (angl. targeting) in težave pri izmenjavi informacij med zavezniškimi silami. Tudi na tem področju je bila podpora ZDA za učinkovitost operacije bistvena; zagotovile so 75 odstotkov zmogljivosti za ISR ${ }^{10}$, prav tako 75 odstotkov letal za oskrbo z gorivom v zraku. Ameriška poveljstva pa so zagotovila tudi več kot sto dodatnih vojaških specialistov za delo v Natovem centru za izbiro ciljev (angl. targeting center), potem ko je postalo jasno, da druge zaveznice nimajo ustrezno izkušenega osebja (Baltrusaitis in Duckenfield, 2012, str. 37-8, Daalder in Stavridis, 2012). Izkušnje iz operacije opozarjajo, da so tudi evropske članice Nata, ki razpolagajo s sodobnimi in zmogljivimi oboroženimi silami, pri izvajanju operacij na kriznih območjih glede nekaterih ključnih zmogljivosti močno odvisne od podpore ZDA. Zaradi težav, ki so se pojavile že v razmeroma omejeni operaciji, se postavlja vprašanje sposobnosti zavezništva, da bi brez podpore ZDA v prihodnje izvajalo obsežne vojaške operacije.

\section{SPOSOBNOST KRIZNEGA POSREDOVANJA V KONTEKSTU RAZVOJA STRATEGIJE IN ZMOGLJIVOSTI NATA}

Operacija v Libiji je bila nedvoumen odraz napredka v razvoju prakse posredovanja mednarodne skupnosti v notranjih konfliktih in potrditev, da je humanitarni vidik lahko pomemben vzrok posredovanja. V praksi pa je operacija poleg doseganja humanitarnih ciljev tudi vplivala na izid spopadov. Postopek sprejemanja resolucije v ZN in izvedba operacije predstavljata uveljavitev načela multilateralizma pri takih posegih. Potek operacije je nakazal prednosti, pa tudi slabosti multulateralizma, vendar kaže, da tovrstna posredovanja ne postajajo univerzalna praksa, zato se pri razmisleku o vlogi Nata v reševanju kriz v svetu najprej postavi vprašanje, v katerih krizah je mogoče pričakovati posredovanje zavezništva. Kateri mednarodnopolitični dejavniki privedejo do take odločitve? Poleg tega, da je bistven interes zaveznic, so zelo pomembni mednarodni kontekst neke krize in njene značilnosti. Dejavnikov, ki vplivajo na to, da se v mednarodni skupnosti oblikuje pripravljenost za posredovanje, je veliko. Brez takšne širše podpore je posredovanje zavezništva malo verjetno. Nato za kakršno koli krizno operacijo potrebuje tudi mednarodno legitimnost in jasen mandat. ${ }^{11} \mathrm{~V}$ primeru Libije je bilo v mednarodni skupnosti razmeroma hitro doseženo soglasje glede posredovanja do stopnje, ki je omogočila sprejetje resolucije Varnostnega sveta ZN. V nekaterih drugih primerih, na primer pri spopadih v Siriji, pa so bili stališča in interesi, ki takega soglasja ne omogočajo, veliko bolj različni. ${ }^{12}$

\footnotetext{
${ }^{10}$ Ključnega pomena so bila predvsem letala EC-130J za elektronsko motenje, GlobalHawk in U-2 ter brezpilotna letala Predator za zagotavljanje informacij s terena in letala KC-135 za oskrbo z gorivom v zraku.

"I Vse dosedanje operacije Nata so imele tudi mandat Varnostnega sveta ZN ali drugo ustrezno podlago za delovanje. Izjema je bila operacija proti ZRJ leta 1999, ki ni imela izrecnega mandata VS ZN, vendar jo je podpirala velika večina članic ZN in je imela visoko legitimnost v mednarodni skupnosti.

${ }_{12}$ Glede možnosti vojaškega posredovanja v Siriji je treba upoštevati dejstvo, da Rusija in Kitajska kot stalni članici Varnostnega sveta posredovanja ne bi odobrili. Poleg tega lahko zasledimo ocene, da vojaško posredovanje ne bi prineslo rešitve vprašanja in tudi ne bi zaustavilo prelivanja krvi, ker bi se spopadi med različnimi akterji v Siriji nadaljevali, tudi če bi bil odstranjen sedanji režim. ZDA in evropske države glede na vojaško zahtevnost takega posegajo nimajo zadostnih vojaških zmogljivosti (Friedman, 2013).
} 
Ena izmed spodbud za posredovanje, kot kaže primer Libije, so lahko humanitarni vzroki. Toda tudi resnost humanitarne krize, število žrtev itn. niso zadostni vzroki, da bi se v mednarodni skupnosti oblikoval dogovor o nujnosti posredovanja. Je pa to pomemben element legitimnosti posredovanja, če je glede tega dosežena odločitev. Humanitarni vzroki so torej lahko pomemben dejavnik odločitve za posredovanje, vendar delujejo v kontekstu $\mathrm{z}$ drugimi interesi in okoliščinami.

V primeru krize v Libiji so sprejetje resolucije ZN in posredovanje v krizi utemeljevali tudi z normo »odgovornost zaščititi $\ll^{13}$ (angl. responsibility to protect) (Daalder, 2012), ki poziva mednarodno skupnost k posredovanju, kadar vlada ne more zaščititi svojega civilnega prebivalstva. Toda kot kaže praksa, ni mogoče pričakovati, da se bo v mednarodni skupnosti v vseh primerih, ko kriza zahteva žrtve med civilnim prebivalstvom, oblikovala pripravljenost posredovati na podlagi te norme. Posebej še, če naj bi posredovanje potekalo tudi z vojaškimi sredstvi. ${ }^{14} \mathrm{~V}$ prihodnosti bo morebitni poseg Nata v neko krizo odvisen od širšega notranjega in mednarodnega konteksta krize; od tega, kakšen preplet stališč, prepričanj in interesov se v povezavi s krizo oblikuje v mednarodni skupnosti.

Najpomembnejša za posredovanje Nata v neki krizi je podpora med njegovimi članicami. Pomembno je, da obstaja interes vsaj nekaterih najpomembnejših zaveznic. V primeru operacij »out of area« od sredine devetdesetih let smo priča dejstvu, da večina Natovih operacij ni imela popolne podpore vseh članic. Soglasnost glede skupne obrambe v primeru napada na zavezništvo je bila $\mathrm{v}$ hladni vojni pričakovana. Drugače pa je, ko gre za odločitve glede vojaških operacij, ki potekajo zunaj koncepta skupne obrambe. ${ }^{15}$ Že v devetdesetih letih so teoretiki opozorili na morebitne težave pri delovanju Nata v takih operacijah. Lepgold (1998, str. 85) ugotavlja, da se mirovne operacije od Natovih tradicionalnih funkcij razlikujejo $\mathrm{v}$ tem, da so v primerjavi z obveznostjo skupne obrambe diskrecijske narave, kar pomeni, da se zaveznice za ukrepanje oziroma sodelovanje v mirovnih operacijah odločajo po lastni presoji. Poleg tega opozarja, da te operacije ne zadevajo teritorialne ali politične integritete članic in bo zato zainteresiranost za njihov uspeh manjša kot v primeru varovanja svojega ozemlja. Na različna stališča članic Nata do morebitnega posredovanja v krizah kažejo tudi razmišljanja, ki upoštevajo, da članice različno zaznavajo ogroženost. Vprašanja varnosti lahko posamezne članice razumejo kot različno ogrožajoče, zaradi česar so različna tudi njihova stališča o tem, kdaj je treba posredovati. Cottey (1998, str. 57) predvideva, da bodo v novem varnostnem okolju, v katerem so varnostne skrbi vedno bolj različne, tudi interesi članic Nata različni, ter opozarja na izkušnje, ki kažejo, da bodo različne koalicije Natovih članic kazale različno stopnjo pripravljenosti za vključevanje v prihodnje vojaške operacije. V zadnjih letih praksa kaže, da bo v prihodnosti razprava med

\footnotetext{
${ }^{13}$ Norma »odgovornost zaščititi« je bila oblikovana v poročilu Mednarodne komisije za intervencijo in suverenost držav iz leta 2001. Leta 2005 je bila ta norma vključena v zaključni dokument letne skupščine OZN.

${ }_{14}$ Odnos do krize v Siriji jasno ilustrira navedeno dilemo. Aprila in maja 2013 je bila mednarodna skupnost mogoče pripravljena pomagati upornikom, vendar pa je bilo videti tudi precejšnjo zadržanost za kakršno koli obliko vojaške pomoči ali celo vojaškega posredovanja.

${ }_{15}$ V angleškem jeziku so za take operacije uveljavili izraz »nonArticle-5 missions«.
} 
članicami o vojaškem posredovanju v krizah najverjetneje potekala ob soočanju različnih stališč in prioritet. Nekatere članice zavezništva so že tradicionalno manj naklonjene vojaškemu posredovanju zunaj svojega ozemlja. V vsakem primeru bodo take razprave odražale tudi različne geopolitične interese članic.

Operacija v Libiji je pokazala, da lahko Nato tudi brez politične podpore nekaterih članic uspešno izvede vojaško posredovanje. Nasprotovanje posredovanju ne pomeni nujno tudi blokade aktivnosti zavezništva. Nemčija je v primeru operacije v Libiji sicer nasprotovala vojaškemu posredovanju, vendar pa je vseskozi podpirala humanitarno posredovanje in tudi ni blokirala Natove odločitve za posredovanje ter zavezništvu s povečanjem svojega delovanja $\mathrm{v}$ aktivnostih zračnega nadzora v Afganistanu celo pomagala pri izvedbi operacije v Libiji (Daalderin Stavridis, 2012). V primeru kriz v prihodnosti bomo v zavezništvu očitno priča tudi različnim stališčem do posredovanja, vendar pa to ne bo nujno pomenilo blokade zavezništva, da se odzove tudi z vojaškimi sredstvi.

Preusmeritev Nata na tako imenovane operacije »out of area« vseskozi spremlja tudi vprašanje zagotavljanja vojaških zmogljivosti za tako delovanje. To se je jasno pokazalo tudi ob Natovem posredovanju v Libiji. Težava je predvsem razkorak med zmogljivostmi ZDA in evropskih zaveznic, ki se kaže pravzaprav že skozi vso zgodovino zavezništva in je bil podlaga za razprave glede delitve bremen. Že v obdobju hladne vojne, posebno od sedemdesetih let naprej, je bilo zaslediti pričakovanja ZDA, da naj evropske zaveznice povečajo svoja vlaganja v obrambo in tako prevzamejo večji delež bremen skupne obrambe. V Natu so s tem ciljem leta 1977 pripravili dolgoročni načrt razvoja, ki je vsem članicam nalagal povečevanje obrambnih izdatkov za tri odstotke na leto (Kugler, 1993, str. 355-58). Toda pričakovanja o izenačenju obrambnih bremen med ZDA in evropskimi zaveznicami se niso nikoli uresničila in tudi po koncu hladne vojne je tako imenovani »razkorak v zmogljivosti« ostal pomembna tema medzavezniških odnosov. Kot navaja Yost (2000, str. 99), znašajo izdatki za obrambo evropskih zaveznic približno 60 odstotkov ameriških izdatkov, vendar pa jim ta znesek zagotavlja samo približno 10 odstotkov zmogljivosti v primerjavi z ZDA. Tako imajo evropske zaveznice $\mathrm{v}$ primerjavi z ZDA manj kot deset odstotkov zmogljivosti za nadzor na strateški ravni ( $\left.{ }^{4} \mathrm{ISR}\right)$, manj kot 20 odstotkov zmogljivosti za zračni transport in manj kot deset odstotkov natančno vodenega streliva.

Razkorak v vojaških zmogljivostih med ZDA in evropskimi zaveznicami se kaže predvsem v sposobnosti nameščanja sil in delovanja zunaj lastnega ozemlja. Je posledica neenakega vlaganja $v$ razvoj vojaških sil. ZDA trenutno namenjajo za obrambo več kot $4 \%$ BDP, v evropskih državah pa je ta delež v povprečju 1,6\%. Med evropskimi članicami Nata so samo Francija, Grčija, Turčija in Velika Britanija leta 2012 dosegale v Natu opredeljeni ciljni delež 2 \% BDP, namenjenega za obrambo; vrsta članic pa je za obrambne izdatke namenila manj kot 1,5\% BDP ali pa se celo približala $1 \%$ (SIPRI Military Expenditure Database, 2012). Na razkorak v vojaških zmogljivostih opozarjajo tudi podatki glede strukture porabe. Medtem ko ZDA ter 
evropske države članice EU skupaj razpolagajo s približno enako velikimi oboroženimi silami, so v ZDA v devetdesetih izdatkom za razvojnoraziskovalno dejavnost namenili 53 milijard evrov, v državah EU pa skupaj 9 milijard. Na podoben razkorak kažejo investicije v opremo ter razvojnoraziskovalno dejavnost na vojaka: v ZDA so znašale 95.476 EUR, v EU pa v povprečju 19.034 EUR (Bugajski in Teleki, 2007). Podatki o izdatkih, ki so ključni za tehnološko raven delovanja oboroženih sil, nam tako pokažejo petkratno razliko med ZDA in povprečjem v evropskih državah.

V analizah po posredovanju v Libiji najdemo ocene, da Nato ni zmožen izvajanja vojaških posegov, če so ZDA zadržane pri zagotavljanju kritičnih vojaških zmogljivosti; Natov koncept "pametne obrambe« (angl. Smart Defence) pa ima trenutno znatne omejitve (Baltrusaitis in Duckenfield 2012, str. 22). Glede na gospodarsko krizo, varčevanje in proračunske usmeritve $\mathrm{v}$ številnih evropskih državah tudi $\mathrm{v}$ prihodnje ni mogoče pričakovati, da bi se razkorak v zmogljivostih med ZDA in evropskimi zaveznicami bistveno zmanjšal. Sposobnost Nata za izvajanje zahtevnih vojaških operacij bo v prihodnje ostajala odvisna od pripravljenosti ZDA za zagotavljanje nekaterih bistvenih vojaških zmogljivosti. Če bi se interes ZDA za tovrstno podporo zmanjšal, kar se je v določeni meri zgodilo že v operaciji v Libiji, pa bi se to znatno odrazilo na sposobnosti Nata za izvajanje vojaških operacij.

V Natu že dlje časa poskušajo povečati ključne vojaške zmogljivosti za izvajanje nalog, ki so v zadnjih dveh desetletjih s spremembami v njegovi strategiji postale temeljne. Leta 1999 so voditelji držav zaveznic sprejeli Pobudo obrambnih zmogljivosti (angl. Defence Capabilites Initiative), katere namen je povečanje učinkovitosti vojaških sil zavezništva. Toda pobuda ni prinesla želenega učinka, saj so se v naslednjih letih obrambni izdatki v ZDA povečali, v evropskih pa upadli, vrzel zmogljivosti pa se je samo še povečala (Vertovšek, 2010, str. 50). Posledično so bile leta 2002 sprejete tako imenovane Praške zaveze zmogljivosti (angl. Prague Capability Commitment), s katerimi so države definirale glavne zmogljivosti, ki jih je treba izboljšati za uspešno izvajanje vseh vrst operacij zavezništva. Ta pobuda je prinesla nekoliko več uspeha kot prejšnja, nekoliko več poudarka pa je bilo na večnacionalnih rešitvah glede zmogljivosti (prav tam, str. 52). Sedanja prizadevanja za dvig vojaških zmogljivosti Nata v razmerah zmanjševanja razpoložljivih finančnih sredstev v Natu potekajo v okviru koncepta "pametna obramba«, ki ga razumejo kot »kulturo sodelovanja, ki zaveznice spodbuja k sodelovanju v razvoju, pridobivanju in vzdrževanju vojaških zmogljivosti za izvajanje najpomembnejših Natovih nalog, opredeljenih s strateškim konceptom « (Nato, 2013). Okrepili naj bi sodelovanje in specializacijo med zaveznicami, tako da bi ohranili vojaške zmogljivosti ob hkratnem zmanjševanju stroškov z razvojem ekonomije obsega, z odstranjevanjem odvečnih sredstev in s specializacijo v nišnih zmogljivostih (Baltrusaitis in Duckenfield, 2012, str. 22). Gre za poskus racionalizacije, pri čemer so določena sredstva $\mathrm{v} »$ skupni rabi«. To pomeni, da vse zaveznice nujno ne razpolagajo z vsemi sredstvi, potrebnimi za vojaško delovanje, temveč si jih delijo z drugimi. Tak pristop zagotavlja ekonomsko racionalnost, pa tudi medsebojno odvisnost zaveznic glede določenih vojaških zmogljivosti. 
Taka odvisnost glede zagotavljanja vojaških zmogljivosti pa lahko, kot je pokazal primer operacije v Libiji, tudi omeji sposobnost delovanja zavezništva. Prav primer nasprotovanja Nemčije vojaškemu posegu in posledično umika osebja iz posadk letal AWACS je spodbudil razmisleke o težavah, ki jih je mogoče pričakovati v zvezi z učinkovitostjo koncepta »pametne obrambe«. Baltrusaitis in Duckenfield (2012, str. 34) opozarjata, da lahko, če država, ki razpolaga s pomembnimi zmogljivostmi za neko operacijo, v njej ne želi sodelovati, to privede do resne ovire v sposobnosti Nata za izvedbo operacije. Ob siceršnjih pričakovanih ekonomskih učinkih "pametne obrambe« ta koncept po drugi strani lahko privede do tega, da zaradi različnih političnih pogledov zaveznic sredstev v »skupni rabi« ni mogoče uporabiti za neko Natovo operacijo.

Vrsta vprašanj glede učinkovitosti Nata in tudi glede učinkovitosti mednarodne skupnosti v reševanju kriz, podobnih libijski krizi, se postavlja tudi z vidika razvoja dogodkov v Libiji po koncu posredovanja Nata. Po letu 2011 so razmere v Libiji politično in varnostno nestabilne. V tem obdobju smo priča nasilnim incidentom, ki obsegajo napade na tuja diplomatska predstavništva, ustanove mednarodnih organizacij in državne ustanove. Sedanji položaj v Libiji je »potencialni toksični varnostni vakuum«, v katerem niti varnostne sile, niti policija, niti vojska niso sposobne zagotavljati varnosti (Gaub, 2013). Povečuje se obseg nasilnega kriminala, vse od atentatov pa do roparskih dejanj. Posebna težava je delovanje različnih milic, oblikovanih v obdobju konflikta, ki zavračajo integracijo v enoten varnostni sistem in si prizadevajo za izvajanje oblastnih funkcij na lokalni ravni. Značilnost libijskega upora je bilo njegovo lokalno in plemensko ozadje. Kot ugotavlja Lacher (2012), je bil opredeljujoči vidik libijske revolucije nastanek lokalnih centrov moči hkrati s procesom razpada države. V tem obdobju je nastajanje uporniških formacij temeljilo na moči lokalne, družinske in plemenske lojalnosti ter na šibkosti državnih institucij. S padcem režima so revolucionarne sile dosegle cilj, ki jih je povezoval v heterogeno koalicijo. Temu je sledil boj za oblast, v katerem so bili glavni akterji predstavniki različnih mest ali plemen (Gaub, 2013). Tako se pozneje mesta, plemena in milice potegujejo za vpliv na lokalni in nacionalni ravni. Širše nacionalne koalicije niso bile oblikovane, Nacionalni prehodni svet pa se je spoprijemal s krizo legitimnosti.

Razmere v Libiji so danes politično in varnostno nestabilne. Hitrega prehoda v stabilnost po dobrih štirih desetletjih diktature tudi ni pričakovati in podobno kot $\mathrm{v}$ drugih državah, kjer je potekala tako imenovana arabska pomlad, je prihodnost precej negotova. Primer operacije v Libiji kaže, da humanitarno posredovanje lahko zmanjša človeške žrtve in trpljenje v nekem konfliktu, vendar pa ne privede nujno do izboljšanja socialnih, varnostnih in političnih razmer. $\mathrm{K}$ doseganju slednjega bi gotovo pripomoglo celovitejše delovanje mednarodne skupnosti, ki pa je v tem primeru izostalo. Zahodne države pravzaprav niso razvile celovite strategije do dogajanj v kontekstu arabske pomladi, deloma zato, ker so jih ta dogajanja presenetila, pa tudi zaradi nekdanje politike do režimov v tej regiji in zaradi osredotočenosti na lastne težave, povezane s finančno in gospodarsko krizo. 
Natova operacija je bila kratkotrajna in omejena na doseganje vojaških ciljev. Širši in trajnejši pristop k reševanju vprašanj zagotavljanja stabilnosti, podoben logiki v Natu razvijajočega se celostnega pristopa, ki bi temeljil na delovanju širšega spektra mednarodnih struktur in organizacij, ni bil oblikovan. Nato kot vojaško-politična organizacija pravzaprav ne more biti središčni nosilec take strategije, pač pa bi tak pristop lahko oblikovale zahodne države s pomembno vlogo EU. Vloga mednarodne skupnosti pri reševanju težav v Libiji je tako zdaj omejena na nekaj posamičnih dejavnosti: septembra 2011 je bila ustanovljena politična misija Združenih narodov (UNSMIL), katere naloga je pomoč pri stabilizaciji razmer v Libiji; EU se reševanja težav v Severni Afriki in na Bližnjem vzhodu loteva z instrumenti evropske sosedske politike in Partnerstva za demokracijo, ki pa so zaradi nezadostne učinkovitosti pogosto predmet kritike. Sredi leta 2013 EU napoveduje, da bo v Libiji v kratkem namestila manjšo misijo (110 oseb) za pomoč pri nadzoru meja; v Natu pa trenutno razmišljajo o možnih vsebinah varnostnega sodelovanja z Libijo (Gaub, 2013). Če posredovanje $\mathrm{v}$ Libiji pomeni v mednarodni politiki korak naprej pri uveljavljanju prakse vojaškega posredovanja s humanitarnimi nameni, pa se zdi, da ostajajo težave z vzpostavitvijo stabilnosti v pokonfliktnem obdobju enako pereče kot do zdaj.

Sklep Natovo posredovanje v Libiji je bilo hitro in učinkovito. Znatno je pripomoglo k zmanjšanju žrtev med libijskimi uporniki in k vzpostavitvi pogojev za odpravo diktatorskega režima Moamerja Gadafija. Vojaško posredovanje je v tem primeru mogoče upravičiti z doseganjem neposrednih humanitarnih ciljev, vendar kaže tudi, da se bodo razmere lahko res trajneje izboljšale šele dolgoročno, pri čemer je lahko pomembna tudi pomoč mednarodne skupnosti. Na to opozarjajo tudi razmere na Kosovu, v Afganistanu in še marsikje drugje.

Posredovanje je opozorilo tudi na pomembna vprašanja glede Natove sposobnosti za delovanje v krizah, kot sta vprašanje politične kohezivnosti med zaveznicami in vprašanje vojaških zmogljivosti za izvajanje operacij zunaj območja zavezništva. Izvajanje operacije v Libiji je pokazalo, da Nato lahko izvede vojaško operacijo tudi, kadar je del zaveznic ne podpira. Pokazalo se je tudi, da je kljub težavam z zagotavljanjem ustreznih vojaških zmogljivosti mogoče najti ustrezne rešitve, ki omogočajo uspešno izvedbo operacije. Pri zagotavljanju Natovih vojaških zmogljivosti so v vsaki zahtevnejši operaciji ZDA še vedno najpomembnejša zaveznica.

Pri izvajanju s svojo strategijo določenih nalog se bo Nato srečeval z vrsto vprašanj, značilnih za delovanje mednarodnih struktur, ki izhajajo iz različnosti interesov in stališč članic ter iz različne percepcije groženj. Med taka vprašanja spada tudi problem delitev bremen med zaveznicami. Glede posredovanja v morebitnih krizah pa bomo najbrž priča večji fleksibilnosti v zavezništvu. To je tudi nujno, če želi Nato ohraniti sposobnost posredovanja. Fleksibilnost bo potrebna tako glede politične podpore operacijam in pripravljenosti članic za sodelovanje v vojaških operacijah kot tudi glede ustreznega zagotavljanja in uporabe vojaških zmogljivosti. 


\section{Literatura}

1. Arnold, M., J., 2008. Intervention. V Snyder C., A., ur. Contemporary Security and Strategy. New York: Palgrave Macmillan.

2. Baltrusaitis, D. F., Duckenfield M. E., 2012. Operation Unified Protector: Triumph or Warning Sign? Baltic Security and Defence Review, 14-2.

3. Bellamy, A., Williams, P., D., 2011. The New Politics of Protection? Côte d'Tvore, Libya and the Responsibility to Protect. International Affairs, 87-4.

4. Bugajski, J., Teleki I., 2007.Atlantic Bridges: America's New European Allies. Rowman\& Littlefield Publishers, Inc.

5. Conflict Barometer 2011.Heidelberg Institute for International Conflict Research. http:// www.hiik.delen/konfliktbarometer, 20. 4. 2013.

6. Cottey, A., 1998. NATO Transformed: the Atlantic Alliance in a New Era. V Park, W., Rees, G. W., ur. Rethinking Security in Post-Cold War Europe. London, New York: Longman.

7. Daalder, I. H., Stavridis J. G., 2012. NATO's Victory in Libya. http://www.foreignaffairs. com/articles/137073/ivo-h-daalder-and-james-g-stavridis/natos-victory-in-libya, 23. 5. 2013.

8. Finnemore, M., 1996. Constructing Norms of Humanitarian Intervention. V Katzenstein, P., ur. The Culture of National Security: Norms and Identity in World Politics. New York: Columbia University Press.

9. Friedman, G., 2013. Redlines and the Problems of Intervention in Syria. Geopolitical Weekly. http://www.stratfor.com/weekly/redlines-and-problems-intervention-syria, 14. 5. 2013.

10. Gaub, F., 2013. Libya: The Struggle for Security. European Union Institute for Security Studies.

11. Harding, T., Day, M., 2011. Libya: Germany replenishes NATO's arsenal of bombs and missiles. http://www.telegraph.co.uk/news/worldnews/europe/germany/8603885/LibyaGermany-replenishes-Natos-arsenal-of-bombs-and-missiles.html, 28. 4. 2013.

12. Human Rights Watch - World Report, 2012. http://www.hrw.org/sites/default/files/reports/ wr2012.pdf, 22. 7. 2013

13. ISS Comment, 2011. No. 34, Vol. 17. http://www.iiss.org/en/publications/strategic\%20 comments/sections/2011-a174/early-military-lessons-from-libya-b416, 15. 10. 2011.

14. Kugler, L. R., 1993. Commitment to Purpose. Santa Monica: RAND.

15. Lacher, W., 2012. The Libyan Revolution and the Rise of Local Power Centres.

16. http://www.iemed.org/observatori-en/arees-danalisi/arxius-adjunts/anuari/med.2012/ lacher_en.pdf

17. Lepgold, J., 1998. NATO's Post-Cold War Collective Action Problem. International Security. 23-1.

18. Nato and Libya, 2011. http://www.nato.int/cps/en/natolive/71679.htm, 18. 4. 2013.

19. Nato, 2013. http://www.nato.int/cps/en/natolive/topics_84268.htm, 19. 4. 2013.

20. Nato-Comprehensive Approach, 2013.

21. http://www.nato.int/cps/en/natolive/topics_51633.htm, 23. 7. 2013.

22. Roth K., 2012. Time to Abandon the Autocrats and Embrace Rights: The International Response to the Arab Spring. V Human Rights Watch-World Report, 2012. http://www. hrw.org/sites/default/files/reports/wr2012.pdf, 22. 7. 2013.

23. Santini H. R., Varvelli A., 2011. The Libyan Crisis Seen from European Capitals. The Brookings Institution. http://www.brookings.edu/research/papers/2011/06/01-libyasantini, 25. 4. 2013.

24. Schmitt E., 2012. NATO Sees Flaws in Air Campaign Against Qaddafi. http://www. nytimes.com/2012/04/15/world/africa/nato-sees-flaws-in-air-campaign-against-qaddafi. html?pagewanted=all\&_r=0, 26. 4. 2013. 
25. SIPRI Military Expenditure Database, 2012. http://milexdata.sipri.org/files/?file=SIPRI+ military+expenditure+database+1988-2012.xlsx, 22. 5. 2013.

26. Strategic Concept, 1999. http://www.nato.int/cps/en/natolive/official_texts_27433.htm, 23. 5. 2013.

27. Strategic Concept 2010 - Active Engagement, Modern Defence. http://www.nato.int/cps/ en/natolive/official_texts_68580.htm?selectedLocale=en, 23. 5. 2013.

28. Vertovšek, R., 2010. Primerjalna analiza razvoja vojaških zmogljivosti novih držav članic Nata. Magistrsko delo. Ljubljana: Fakulteta za družbene vede.

29. WHO Monthly Highlights, 2011. http://www.who.int/hac/donorinfo/highlights, 5. 4. 2013.

30. Yost, S. D., 2000. The NATO Capabilities Gap and the European Union. Survival. 42- 4. 